\title{
Key to the larval stages of aquatic true flies (Diptera), based on the operational taxa list for running waters in Germany
}

\author{
A. Sundermann ${ }^{1 *}$, S. Lohse ${ }^{1}$, L.A. Beck ${ }^{2}$, P. Haase ${ }^{1}$ \\ ${ }^{1}$ Senckenberg Research Institute and Natural History Museum, Department of Limnology and Conservation, Clamecystrasse 12, D-63571 \\ Gelnhausen, Germany \\ ${ }^{2}$ Philipps-University Marburg, Department of Biology, Zoology, Marburg, Germany
}

\begin{abstract}
The aquatic larvae of the Diptera are often the most abundant and most diverse group of the benthic macroinvertebrate fauna. They are able to survive in and colonise practically all freshwater habitats, and some species can tolerate harsh environmental conditions. They are therefore both a qualitatively and quantitatively important group of biological indicators for assessing freshwater systems. On the other hand their determination at the species level is very difficult. This is in part due to a lack of taxonomic work in the group, but also the absence of comprehensive determination keys, that meet the needs of water managers. As a result, the aquatic larvae of the Diptera often play a subordinate role in water management. In light of the EU Water Framework Directive the present work is a first step in improving the integration of the important group of the Diptera in water management practice: a comprehensive determination key, which is geared at water managers. The key includes 60 taxa, largely at the family and genus level. In contrast to already existing keys the present work tries to differentiate the taxa on the basis of simple and user-friendly characters. Numerous figures allow for easy checking of determination results. The key is applicable in Germany, Scandinavia, Great Britain and the Benelux states. Mainly taxa from running water systems are considered, but the key can also be used at the family level to determine taxa from standing water bodies.
\end{abstract}

Keywords: Dichotomous key, aquatic diptera, operational taxa list, water framework directive

\section{Introduction}

With worldwide over 118000 species, the group of the Diptera represents one of the richest orders of insects next to the Coleoptera and Lepidoptera (Westheide \& Rieger 1996). Most Diptera are terrestrial, with aquatic habitats only inhabited by a small fraction of species.

Within aquatic ecosystems however, Diptera play an important role: more than half of the recorded aquatic insects are Diptera (see Illies 1978). They colonise practically all kind of freshwater systems and in many cases they are the most abundant taxa. This last aspect is clearly be shown on a data set from 95 macroinvertebrate samples from a national survey in Germany (Haase et al. 2004a). In this project samples were taken from 18 different stream types (Pottgiesser \& Sommerhaeuser 2003) representing four ecoregions (Illies 1978) (Tab. 1). All samples were taken following the standardised sampling and sorting protocol of Haase et al. (2004b). This protocol ensures that samples are

\footnotetext{
* Corresponding author : E-mail: Andrea.Sundermann@ senckenberg.de
}

treated equally and that the invertebrates are determined to a defined taxonomic level so that samples are comparable concerning number of individuals and number of taxa.

Table 1. Number of samples by geographical region (according to Illies (1978)).

\begin{tabular}{lc}
\hline $\begin{array}{l}\text { Geographical regions } \\
\text { according to Illies (1978) }\end{array}$ & $\begin{array}{c}\text { Number of } \\
\text { datasets }\end{array}$ \\
\hline Ecoregion 4: Alps & 3 \\
Ecoregion 8: Western mountains & 9 \\
Ecoregion 9: Central mountains & 42 \\
Ecoregion 14: Lowlands & 41 \\
\hline
\end{tabular}

Figure A shows the number of taxa and individuals from different taxonomic groups recorded in the study. With respect to number of individuals the Diptera present the largest group (U-Test $\mathrm{p}<0.00$; Statistica 6.1 (Statsoft 2002)). The number of taxa in Diptera found in the samples was also higher than those of other taxo- 
nomic groups. However, the significance of this result was not tested because of different taxonomic resolution in these groups. But it seems obvious that differences would be even more pronounced if all taxa were identified at species level.
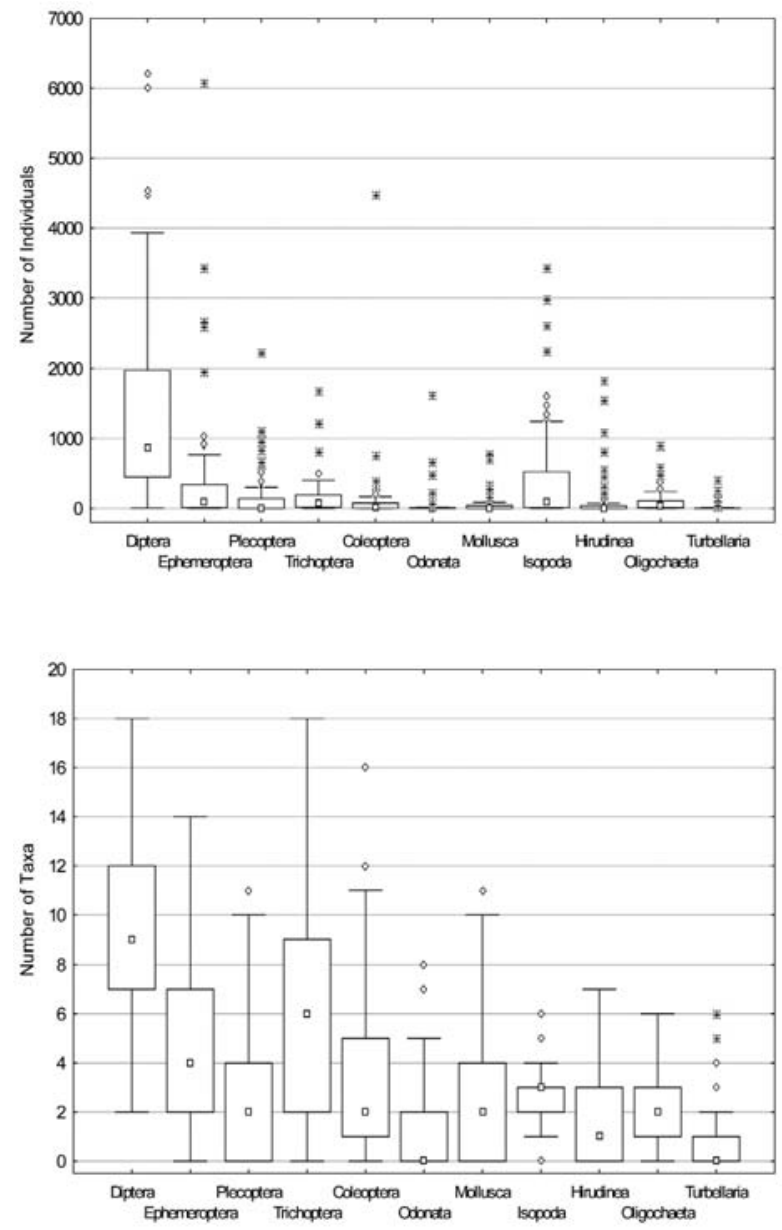

Fig. A. Number of individuals and taxa in different taxonomic groups. Box Plots: $\square$ indicates median; box indicates $25-75^{\text {th }}$ percentile range; $\bigcirc$ indicate outliers; $\boldsymbol{+}$ indicate extreme values. $N=95$

Besides their importance with respect to number of taxa and abundance, Diptera occur in all kinds of freshwater ecosystems and unlike other taxonomic groups in both pristine and degraded systems. Some species are able to tolerate harsh or poor ecological conditions (e.g. water pollution or structural perturbations) and are often the only taxa which still survive in extremely degraded sites. This makes them a very important group for bio-indication in freshwater systems.

\section{General situation of the determination of Diptera larvae}

Unfortunately the determination of Diptera larvae is often not easy. This is mainly for the following reasons: A large number of Diptera larvae are still unknown or undescribed and the identification of many genera and species is only possible with a considerable preparatory effort. Even then, determinations can be difficult and often require expert knowledge.

Another problem arises from the available determination literature: Presently available keys can generally be considered to belong to one of two groups: 1) classical taxonomic-systematic works and 2) simpler keys for less taxonomically or systematically oriented users. For the Diptera, there is a problem with respect to the first group of keys: due to its size and the incomplete taxonomic knowledge of the group, the necessary information is divided among many different keys. Many of these keys are incomplete and often written in different languages. In the second group of keys, simplification often comes at the cost of taxonomic detail and consequently mistakes in determinations are common. The present work combines the advantages of these two common approaches, while minimising their weaknesses.

To date, determinations were primarily based on the works of Nilsson (1997), Smith (1989), Rivosecchi (1984) and Rozkosny (1980), which cover the geographic regions of northern Europe, Italy and southeastern Europe, respectively. The latter two works are written in Italian and Czech, limiting their applicability outside their immediate region. Due to the fact that Nilsson (1997) and Smith (1989) only cover the region of northern Europe, for central Europe no comprehensive key containing all the relevant taxa and written in a language widely comprehensible was previously available.

Another difficulty is that Nilsson (1997) and Smith (1989) are using an unduly technical feature right at the beginning of their keys in order to separate the two (three) groups of Brachycera/Cyclorrhapha and Nematocera. According to their keys, the first group have mandibles which move in a vertical plane whereas the mandibles of the latter move in a horizontal plane. Independent of the fact that the mandibles of the Diptera larvae are often hard to see, some exceptions result in mismatching certain taxa to their corresponding taxonomical group (e.g. Pilaria sp. (Limoniidae) or the family of Syrphidae). In the case of Syrphidae, strongly reduced mandibles make it im- 
possible to categorize this group either to Nematocera or Brachycera/Cyclorrhapha.

The deficiency in taxonomic knowledge and the inadequacy of keys have caused water managers to largely ignore or underestimate the importance of Diptera, thus limiting their value in water management practice. With the implementation of the EU-WFD this aspect became a serious problem.

\section{Development of a key for the larvae of aquatic Diptera}

In order to facilitate the integration of aquatic Diptera into water management practice, the aim of the present work was to develop a key which meets the requirements of water managers. Within this context, the present key should also close the gap of a missing, comprehensive key for central Europe. Moreover the structure of the present work differs from already available keys. The most significant difference is that the unduly technical character, the working direction of the mandibles, is not addressed right at the beginning of the key. So the key presented here is an attempt to compile a comprehensive key for central Europe, which meets the requirements of water managers, but maintains a high level of taxonomic-systematic exactness.

\section{Using the Key}

The basis for the key is the operational taxa list (Haase et al. 2006), which presently contains 67 taxa in the larval stages that are relevant for water management practices and represents the taxonomic basis for implementation of the EU WFD in Germany. By gearing the key at determining the taxa from the operational taxa list, the key becomes relevant for processing all macroinvertebrate samples taken from streams, which are meant for assessment or monitoring in the implementation of the EU WFD.

For practical reasons, only those taxa were included in the operational taxa list - and thus in this key which occur in running waters relevant to EU WFD assessment and monitoring. Very rare semi-aquatic or semi-terrestrial taxa do not feature in the key. Determining such taxa is not possible with the presented key. However, by comparing specimens with the numerous figures given in the key, misidentifications can easily be avoided. A slight risk of misinterpretations is taken into account for routine assessment pro- tocols, because the work effort would greatly increase if a more comprehensive key is used.

The key can be used in Germany and Scandinavia (Denmark, Finland, Norway, and Sweden), Great Britain and the Benelux States (Netherlands, Luxembourg and Belgium). At the family level, the key can also be used in standing water bodies. In comparison to previously available keys (Nilsson 1997 \& Smith 1989) the benefit of the present work is the simplicity and the user-friendliness, so that the Diptera larvae can easily determined with a minimal expenditure of time. The nomenclature follows Schumann et al. (1999).

\section{Structure of the key}

The first part of the key addresses the differentiation of individual families. Exceptions are the families Ceratopogonidae and Muscidae. Taxa of these families and one species of the Limoniidae are determined to higher levels in the first section of the key for practical reasons.

The operational taxa list suggests more detailed determination of specimens from single families. Keys to the genera and some species of these families are given in the second part of the key.

Sizes in the drawings are given as a general orientation. In speciose families, like the Chironomidae, the sizes between species can vary considerably. This size variance could not be accounted for in detail.

\section{Additional literature for further determi- nation of certain families}

In the present key determination of certain families is limited to those taxonomic levels which are listed in the operational taxalist for running waters in Germany. However, the operational taxalist does not restrict the level of determination. In fact, further determination is preferred even though it is not necessary in terms of assessing running waters in Germany. $\mathrm{Ne}$ vertheless the following literature may be helpful for further determination of certain families: Nilsson (1997), Papp \& Darvas (1997, 1998, 2000), Disney (1999) and Bass (1998). For Chaoboridae, Thaumaleidae, Stratiomyidae, Tabanidae and Sciomyzidae rather good keys exist (Saether 2002, Wagner 2002, Rozkosny 2000, 2002, Kniepert 2000). Theses keys cover the region of Central Europe, but they are written in German. 


\section{Key to the families for the last instar larvae}

1 Habitus as in Figs. 1a, b. Three or four adhesive ventral discs on each segment, gills head-on, lamelliform. Colour dark brown to black. Pupae of the Blephariceridae; further determination with Frutiger \& Jolidon (2000)

$1 *$ Habitus not as in Figs. 1a, b. 2
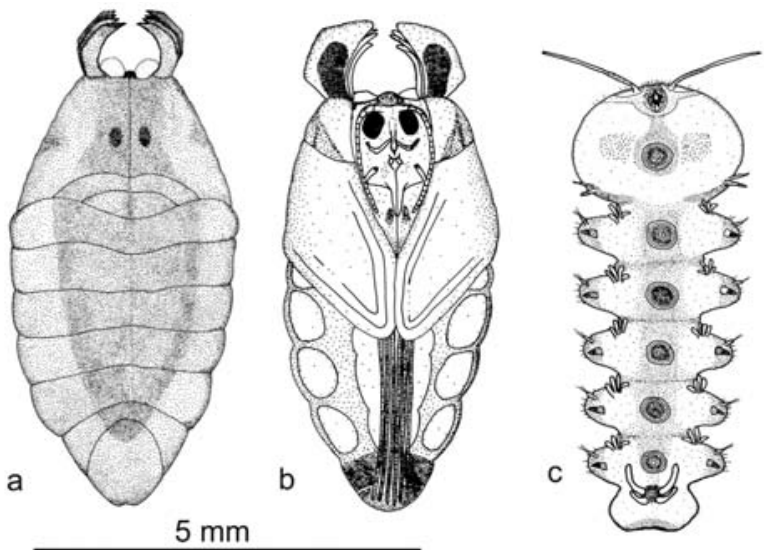

Fig. 1. Blephariceridae. Pupae in dorsal (a) and ventral (b) view. (c) Larvae in ventral view.

2 Head capsule almost completely sclerotised (eucephal), see Figs 2a-e (Exception: Larvae of Blephariceridae, see Fig. 1c). Head capsule normally not retractable into the thorax. 3

$2 *$ Sclerotisation of head capsule incomplete (hemicephal) or sclerotised segments reduced to a hypopharyngeal sceleton (acephal) (Figs 3a-d). Head normally at least partly retractable into the thorax.
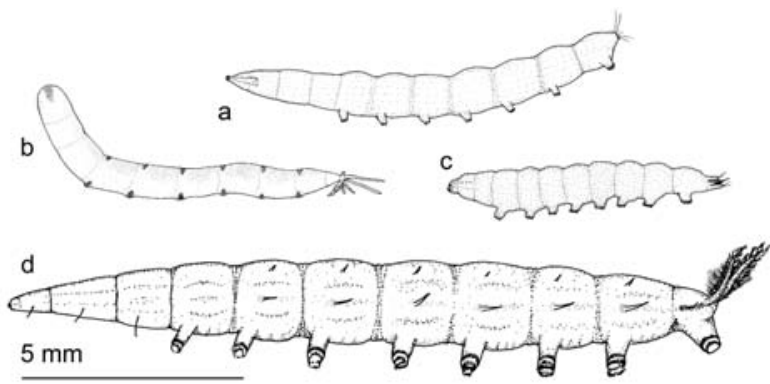

Fig. 3. Examples of larvae with hemi- or acephale (partly sclerotised) head capsule. (a) Empididae, Chelifera Macquart, 1823, (b) Limoniidae, Antocha Osten-Sacken, 1860, (c) Empididae, Clinocerinae, (d) Athericidae, Atherix ibis (Fabricius, 1798).

3 A row of adhesive discs on the ventral side of the body (Fig. 1c), only six body segments. Larvae of the Blephariceridae; further determination with Frutiger \& Jolidon (2000).

$3 *$ Adhesive discs are missing or arranged otherwise, number of body segments $\geq 9$. 4

4 Pseudopodia (with an apical row of hooks) on thorax- and/or abdominal segments (Figs 2a- c, 3a, c-d, $4 \mathrm{c}-\mathrm{d})$. Sometimes the pseudopodia are retracted into the body, in the majority of these cases the hooks are silhouetted against the brighter body. 5

4* Pseudopodia are missing (Figs 2 d-e, 3 b). ...... 11

5 Pseudopodia only on abdominal segments............. 6

$5^{*}$ Pseudopodia only on thoracic segments or on thoracic and abdominal segments. 7

6 Pseudopodia on abdominal segments 1 and 2, characteristic habitus (Fig. 2 c). Ventral side of some abdominal segments with a row of hooks. Dixidae (further determination on page 70) a

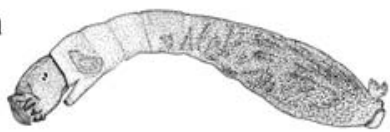

C

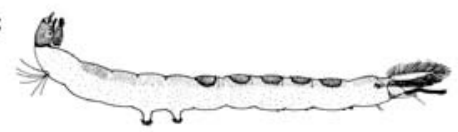

e

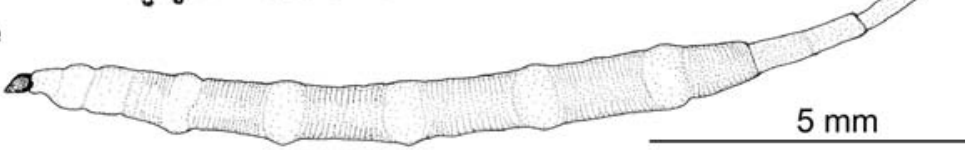

Fig. 2. Examples of larvae with an eucephale (completely sclerotised) head capsule. (a) Simuliidae, (b) Chironomidae, (c) Dixidae, (d) Psychodidae, (e) Ptychopteridae, Ptychoptera Meigen, 1803.

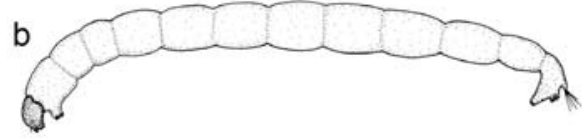

d

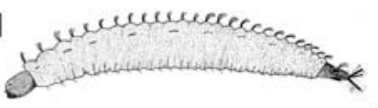

$5 \mathrm{~mm}$ 


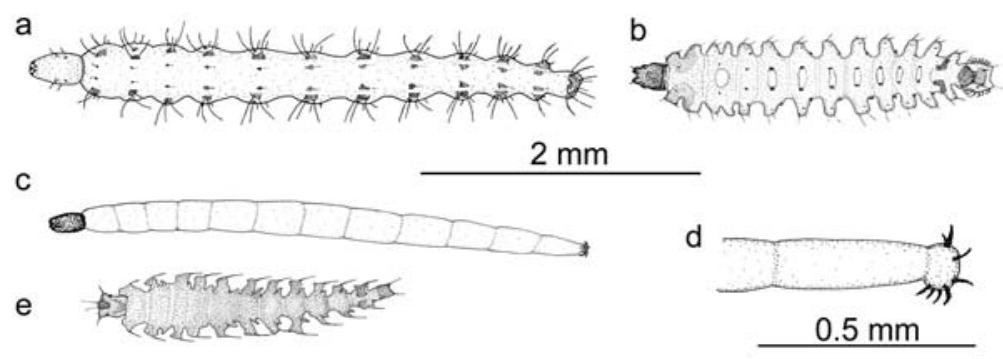

Fig. 4. Ceratopogonidae. (a) Forcipomyia, Meigen, 1818, (b) Atrichopogon Kieffer, 1906, (c) Dasyheleinae, (d) Dasyheleinae, pseudopodia on the last abdominal segment, modified according to Hennig (1950), (e) Atrichopogon.

6* Pseudopodia (unpaired) on the last abdominal segment are retractable and flexible, and have long hooks (Figs $4 \mathrm{c}-\mathrm{d}$ ). Sometimes the pseudopodia are retracted into the body (see comment under 4).......Dasyheleinae (Ceratopogonidae)

7 Pseudopodia (unpaired) on the first segment of the thorax. Posterior part of the body is broadest. The last abdominal segment with a circle of hooks (adhesive disc). Habitus as in Fig. 2 a. Simuliidae (further determination on page 70)

$7 *$ Characters different, habitus not as in Fig. 2 a....8

8 Body with numerous lateral appendages and/or long setae. The latter are inflexible, dark brown and directed backwards, habitus as in Figs 4 a-b, e. Body is partially dorso-ventrally flattened. 9

8* Body without long appendages. If setae are present, then more flexible and not as described above. 10

9 Body with long lateral appendages, normally dorso-ventrally flattened. Habitus as in Figs 4 b,e. Atrichopogon Kieffer, 1906, (Ceratopogonidae)

9* Body cylindrical with long setae, habitus as in Fig. 4 a. Forcipomyia Meigen, 1818, (Ceratopogonidae)

10 Thorax and abdominal segments are dorsally intensely sclerotised. The dorsal side of the body is therefore much darker than the ventral side. Last abdominal segment with a cremaster (a cluster of spines at tip). Spiracles on the lateral side of the first thoracal and the eighth abdominal segment (Fig. 5 a)......Thaumaleidae

$10^{*}$ No intense sclerotisation of thoracal and abdominal segments. Dorsal side of the body is not darker than the ventral side. The last abdominal segment with paired pseudopodia. Without spiracles. Habitus as in Fig. 2 b. Chironomidae (further determination on page 69)

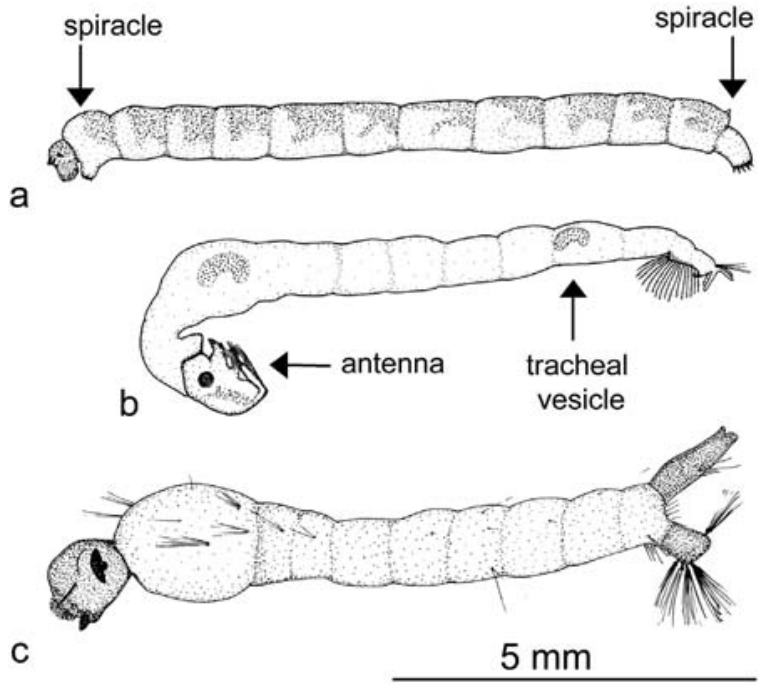

Fig. 5. (a) Thaumaleidae, (b) Chaoboridae, (c) Culicidae.

11 Thoracic segments fused to one segment, broader than the other segments. 12

11* Thoracic segments can be distinguished as three separate units. 13

12 Antennae used as a prehensile organ, seventh abdominal segment normally with paired (pigmented) tracheal vesicles (Fig. 5 b). Chaoboridae

12* Antennae not used as a prehensile organ, paired (pigmented) tracheal vesicles are missing, habitus as in Fig. 5 c. Culicidae

13 Visible pseudosegmentation (apparently 26 body segments) (Fig. 6 a). The majority with sclerotised plates on most of the pseudosegments, sometimes theses sclerotised segments are greatly reduced. Psychodidae (further determination on page 70)

$13 *$ No pseudosegmentation, less than 26 visible body segments. 


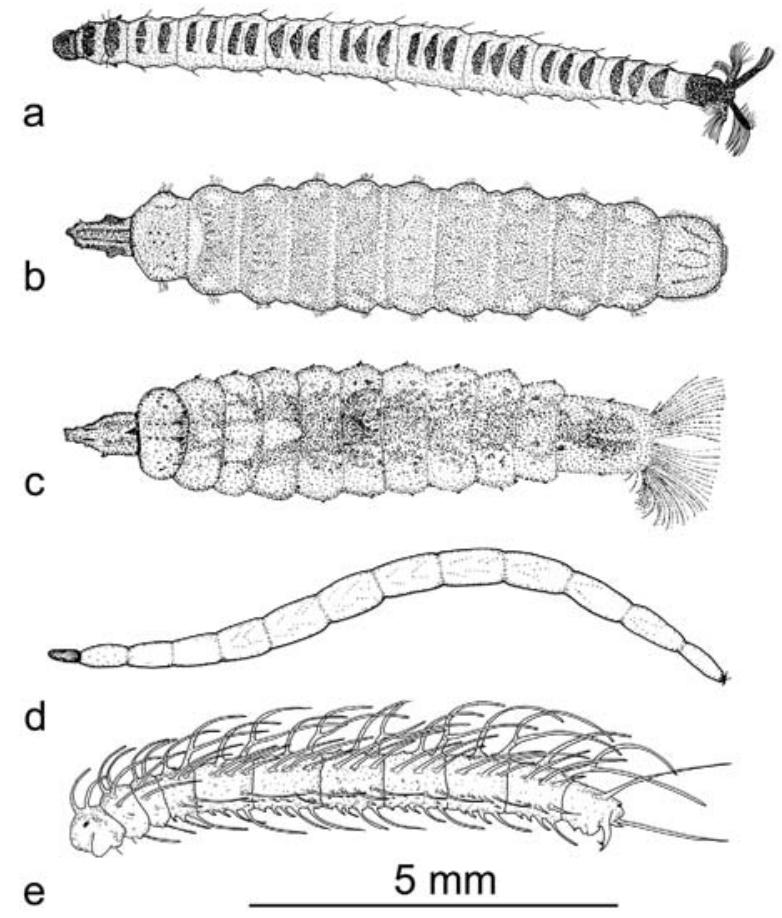

Fig. 6. (a) Psychodidae, (b) Stratiomyidae, (c) Ceratopogoninae, (d) Cylindrotomidae, modified according to Hennig (1950).

14 Surface of body completely sclerotised, looks granulose and firm. Abdominal segments normally dorso-ventrally flattened (Fig. 6 b-c).......Stratiomyidae (further determination on page 71)

$14^{*}$ Surface of body not completely sclerotised. Abdominal segments cylindrical, long and slender. ......15

15 With an extendable respiratory tube at the end of the abdomen (Fig. 2 e).

1803, (Ptychopteridae)

$15^{*}$ Without an extendable respiratory tube at the end of the abdomen. Habitus needle-shaped and cylindrical (Fig. 6 d). .........Ceratopogoninae / Palpomyiinae (Ceratopogonidae)

16 An unpaired extendable repiratory tube at the end of the abdomen.

16* An unpaired extendable repiratory tube at the end of the abdomen is missing. 18

\section{Triplet}

$17^{*}$ The last segment of the respiratory tube is divided into two branches (Fig. 7 a) mandibles are normally developed. Ephydridae a
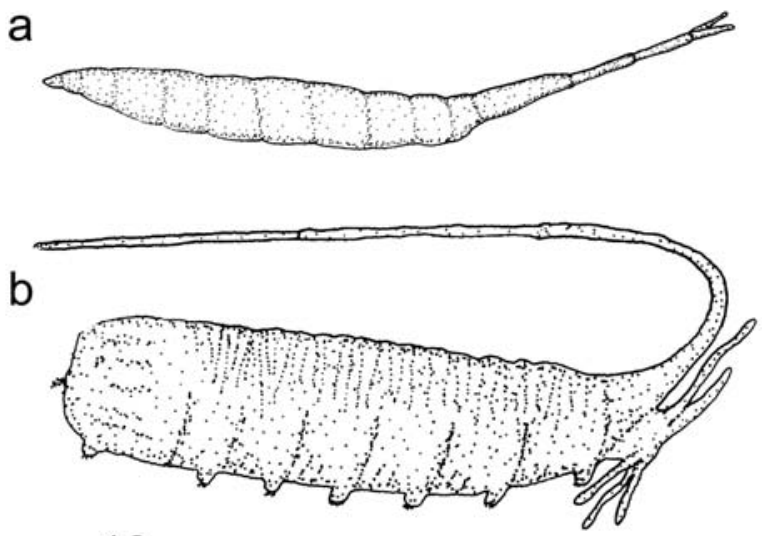

$10 \mathrm{~mm}$

Fig. 7. (a) Ephydridae, (b) Syrphidae, modified according to Hennig (1952).

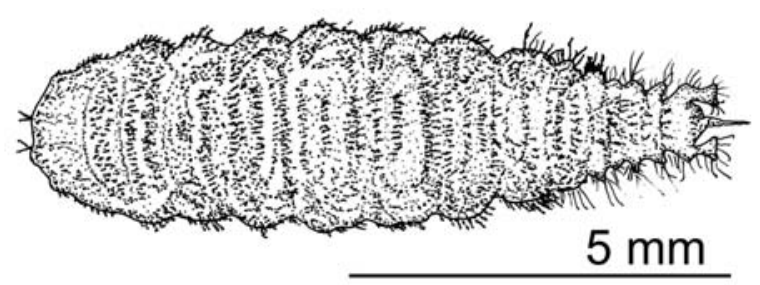

Fig. 8. Syrphidae.

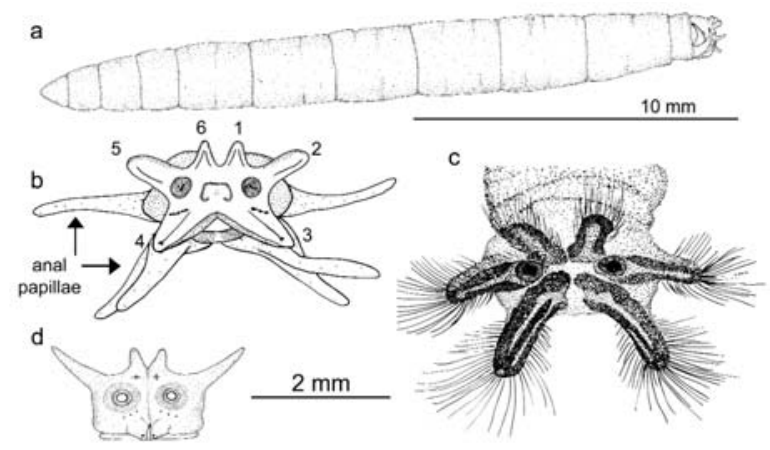

Fig. 10. Tipulidae, Tipula Linnaeus, 1758. (a) Habitus, (b-d) spiracular field at the last abdominal segment (b) with 6 lobes (1-6), in addition with 3 pairs of anal papillae (see arrow), (c) spiracular field at the last abdominal segment with partly reduced lobes.

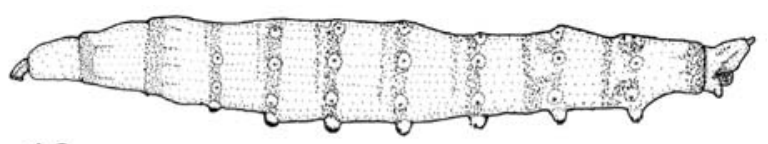
$10 \mathrm{~mm}$

Fig. 11. Tabanidae. 
a

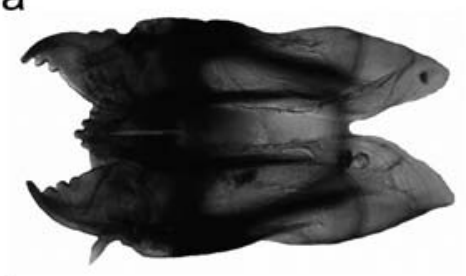

b

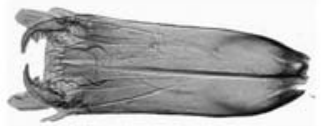

C

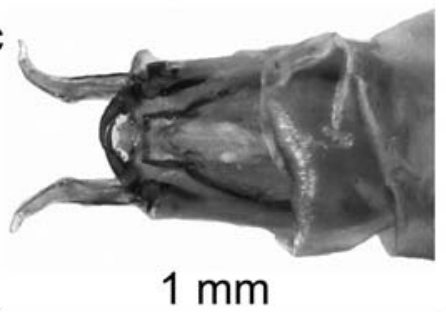

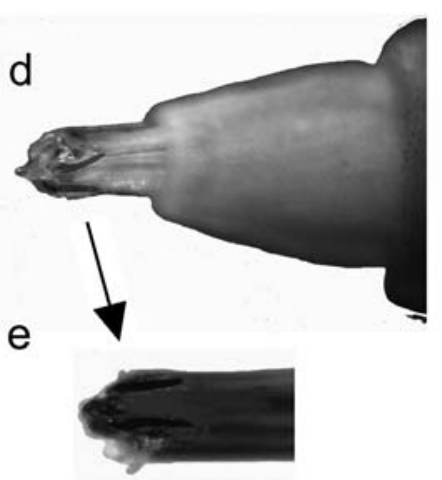

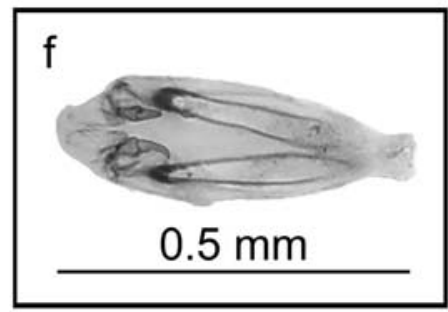

Fig. 9. Cephalopharyngeal skeletons or head capsules in ventral view. (a-c) Limoniidae/Pediciidae, (a) Antocha Osten-Sacken, 1860, (b) Dicranota Zetterstedt, 1838, (c) Eloeophila Rondani,1856, mandibles move in a horizontal plane. (d-e) Athericidae, Atherix ibis (Fabricius, 1798), (f) Limoniidae, Pilaria Sintensis, 1889, mandibles move in a vertical plane.

$17 * *$ The respiratory tube is as long or even longer than the larvae (Fig. 7 b) and mandibles are highly reduced. Eristalinae Syrphidae

$17 * * *$ Habitus as in Fig. 8. other Syrphidae

18 Mandibles move against each other on a horizontal plane (Fig. 9 a-c). 19

$18^{*}$ Mandibles move parallel to each other on a vertical plane (Fig. 9 d-f). 21

19 Abdominal segments (dorsal) with divided or toothed appendages, reaching a length of at least half of the width of the body (Fig. 6 e)...........Cylindrotomidae (further determination on page 70)

19* Abdominal segments with short or without appendages. Appendages are clearly shorter than half of the width of the body. . .20

20 Spiracular field (last abdominal segment) with 6 appendages (Figs $10 \mathrm{~b}-\mathrm{d}$ ), lobes cylindrical or flattened, reduced to some extent (Fig. 10 d), habitus as in Fig. 10 a. ..Tipulidae (further determination on page 72)

$20 *$ Spiracular field surrounded by $\leq 5$ lobes. (further determination on page 72 )
21 Three or four pairs of pseudopodia on each abdominal segment (Fig. 11). Tabanidae (further determination on page 71)

$21^{*}$ At most one pair of pseudopodia or creeping welts on each abdominal segment. Creeping welts are situated at the border of two segments and normally have a transverse row of small hooks. . .22

22 Abdominal segments dorsal and/or lateral with long appendages, habitus as in Fig. 3 d or Fig. 15 a-b. Athericidae (further determination on page 68)

22* Abdominal segments without long appendages.

23 Pseudopodia visible (Fig. 3 a, c). .........Empididae (further determination on page 70)

23* Pseudopodia are missing. Creeping welts may be present.

24 Ventral appendages on the last abdominal segment with long, golden hairs. Ventral lobes with a characteristic pattern (Fig. 12 f). Habitus as in Fig. 12 c.

Pilaria Sintensis, 1889 (Limoniidae) 
24* Last abdominal segment not as described above, without long, golden hairs. 25

25 Four conical or cone-shaped appendages on the last abdominal segment (Figs 12 d-e). Habitus like in Figs 12 a-b. 26

$25^{*}$ Last abdominal segment different, not as in Figs 12 d-e. . .27

26 Dorsal and ventral appendages on the last abdominal segment are of equal length (Fig. $12 \mathrm{~d}$ ). Chrysopilus Macquart, 1826 (Rhagionidae)

26* Dorsal and ventral appendages on the last abdominal segment are different in length (Fig. 12 e). Dolichopodidae
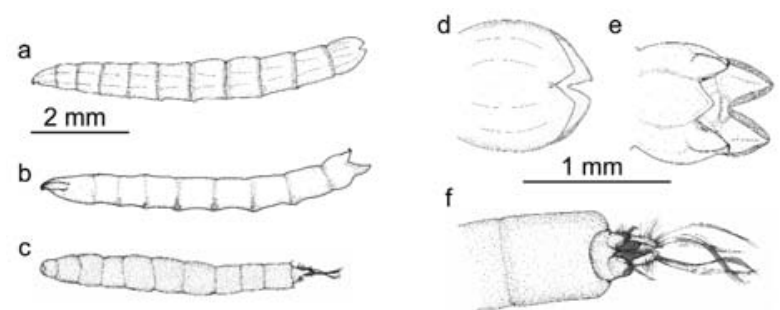

Fig. 12. (a) Rhagionidae, Chrysopilus Macquart, 1826, (b) Dolichopodidae, (c) Pilaria Sintenis, 1889. (d-f) last abdominal segment from dorsal view, (d) Chrysopilus, (e) Dolichopodidae, (f) Pilaria .

27 The last abdominal segment with four divergent appendages. Appendages are directed forward or outward, stiff and barely movable. Habitus as in Fig. 13 a.

.... Limnophora Robineau-Desvoidy, 1830, (Muscidae)

27* Habitus not as in Fig. 13 a, appendages not divergent. 28

28 Abdominal segments without any appendages, only with two prominent spiracular fields (Fig. $13 \mathrm{c}$ ). Habitus as in Fig. 13 b.................... Lispe Latreille, 1796, (Muscidae)

28* Spiracular field on the last abdominal segment surrounded by several appendages (Fig. 14 b). Habitus as in Fig. 14 a.

Sciomyzidae
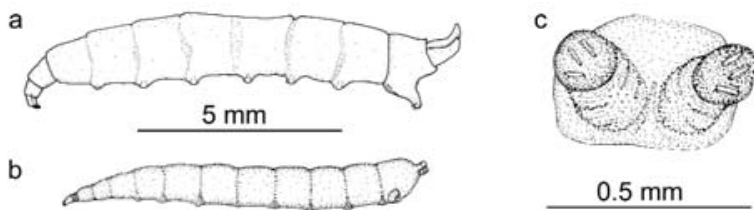

b

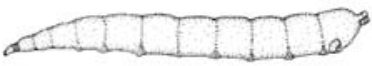

Fig. 13. (a) Muscidae, Limnophora Robineau-Desvoidy, 1830, (b-c) Muscidae, Lispe Latreille, 1796, (b) habitus, (c) last abdominal segment with spiracular field.

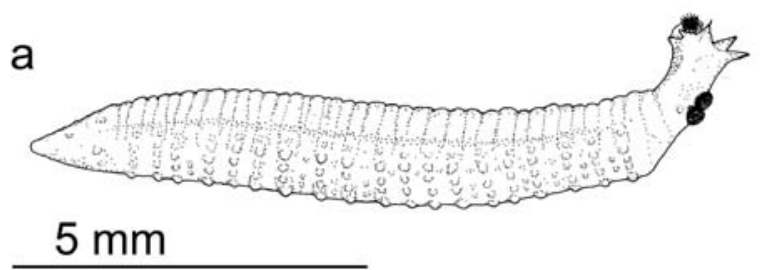

b

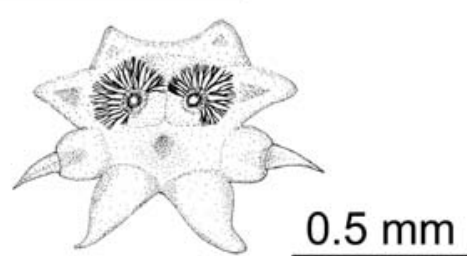

Fig. 14. (a-b) Sciomyzidae, (a) habitus, (b) last abdominal segment.

\section{Key for further determination of selected families:}

\section{Athericidae:}

1 Abdominal segments 6-8 with long filamentous appendages, which can reach a length equivalent to half of the body length (Fig. 15 a). .......Atrichops crassipes (Meigen, 1820)

$1 *$ Abdominal segments 6-8 without such long appendages.

2 The hooks of the outer and middle rows on the pseudopodia are of equal length (Fig. $15 \mathrm{~d}$ ). Dorsal and lateral abdominal appendages are more or less of equal length (Fig. 15 b)...Ibisia marginata (Fabricius, 1781)

$2 *$ The hooks of the outer and middle rows on the pseudopodia are different in length, outer row is shorter than the middle row (Fig. $15 \mathrm{c}$ ). The abdominal segments with dorsal appendages are shorter than the lateral ones (Fig. 3 d). Atherix ibis (Fabricius, 1798)

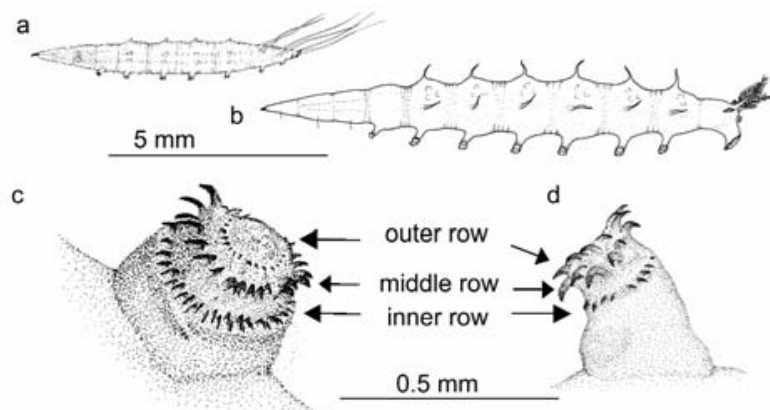

Fig. 15. Athericidae. (a) Atrichops crassipes (Meigen1820), (b) Ibisia marginata (Fabricius, 1781), (c-d) row of hooks on the pseudopodia, (c) Atherix ibis (Fabricius, 1798), (d) Ibisia marginata . 


\section{Chironomidae:}

1 Head capsule oval (Fig.16 a) or egg-shaped, with canals into which the antennae can be retracted. Antennae often retracted to a different degree, i.e. right and left antenna appear to be different in length. (Fig. 16 a). Tanypodinae

$1 *$ Head capsule round. Antenna can not be retracted.

2 Characteristic pattern on the ventral site of the head capsule (Fig. 16 e). Ventromental plates with long hairs.

Prodiamesa olivacea (Meigen, 1818)

2* Characteristic pattern (Fig. 16 e) not in combination with long hairs on the ventromental plates. 3

3 Eyes are arranged above each other in a vertical plane. In most cases, there are two independent eyespots (Fig. 16 b). Ventromental plates on the ventral side of the head capsule (see arrow in Figs $16 \mathrm{f}-\mathrm{g}$ ). 4 (Chironominae)
3* Eyes are arranged behind on another in a horizontal plane or if eyes are arranged in a vertical plane, there are no ventromental plates on the ventral side of the head capsule (Fig. $16 \mathrm{~d}$ ). Eyespots can be close together, often appearing like a comma (Fig. 16 c). Chironomidae Gen. sp. (p.p.)

4 Antennae often shorter than half of the lenght of the head capsule. Ventromental plattes appear triangular, they are widely separated from each other. (Fig. 16 f).

..Chironomini

4* Antennae often as long or longer than half of the lenght of the head capsule. Antennae based on a pedestal, which is longer than wide (see arrow in Fig. 16 b). Space between ventromental plates is in most cases shorter than the width of the median mental tooth. Shape of the ventromental plates is often long and slender (Fig. $16 \mathrm{~g}$ ).

...Tanytarsini

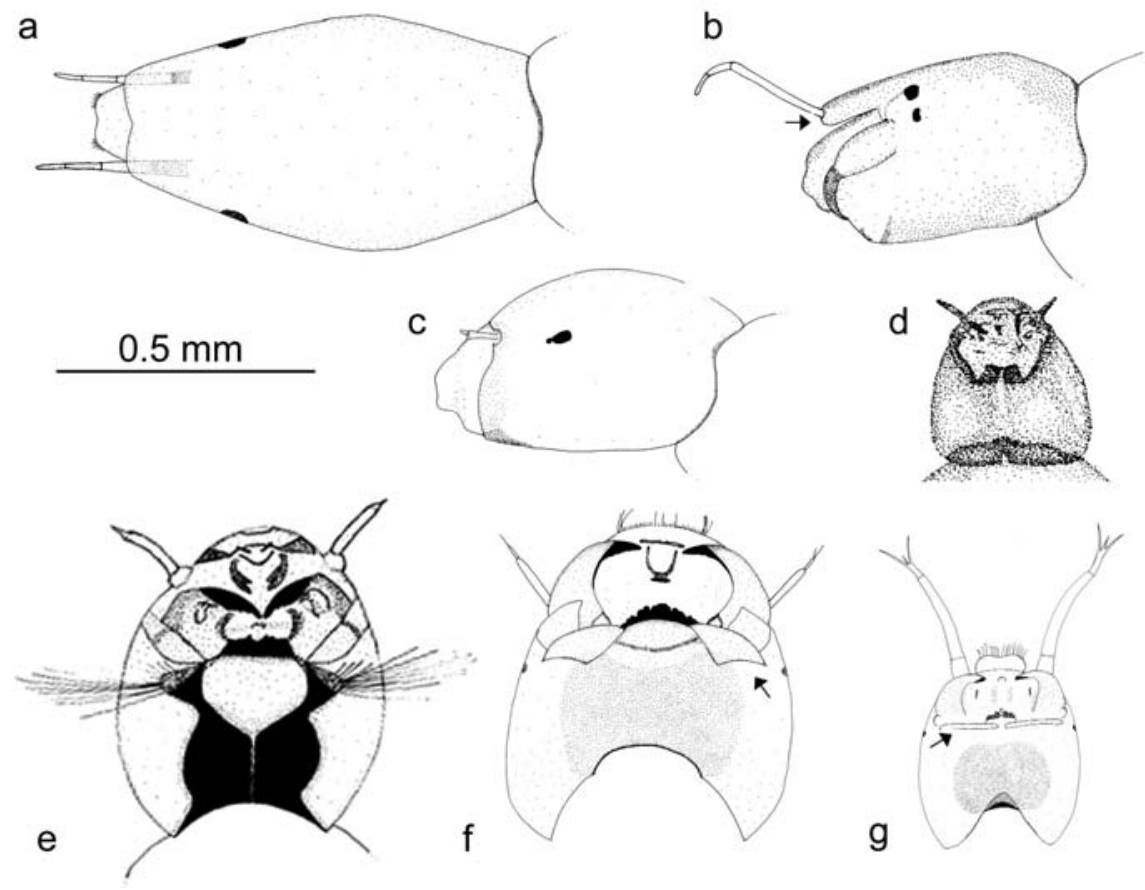

Fig. 16. Head capsules of chironomidae. (a) Tanypodinae, lateral view, (b) Tanytarsini, lateral view, (c) Orthocladiinae, lateral view, (d) Orthocladiinae, ventral view (e) Prodiamesa olivacea (Meigen, 1818), ventral view, (f) Chironomini, ventral view, $(\mathrm{g})$ Tanytarsini, ventral view. 


\section{Cylindrotomidae:}

1 Appendages on the thorax and abdomen divided into two branches, habitus as in Fig. 6 e.......Phalacrocera replicata (Linnaeus, 1758)

1' Appendages on thorax and abdomen not divided into two branches, but they are serrate. (Fig. 17). Habitus is similar to Fig. 6 e.

(Schummel, 1829)

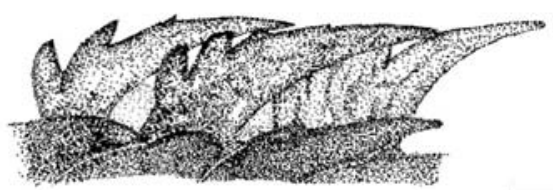

$1 \mathrm{~mm}$

Fig. 17. Triogma trisulcata (Schummel, 1829), serrate appendages.

\section{Dixidae:}

1 Cremaster (a circle of spinules) (Fig. 18) on the dorsal side of five or more abdominal segments. Habitus as in Fig. 2 c.

Dixa Meigen, 1818

1* Abdominal segments without a dorsal cremaster. Habitus similar to Fig. 2 c.. Shannon, 1924
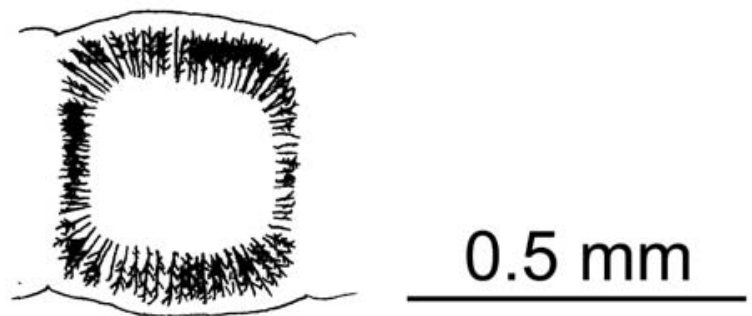

Fig. 18. Dixa Meigen, 1818, detail drawing of a cremaster on the abdominal segment, dorsal view.

\section{Empididae:}

1 Seven pairs of pseudopodia (Fig. 3 a). 2

$1 *$ Eight pairs of pseudopodia (Fig. 3 c). (Dorso-lateral appendages on the last abdominal segment are normally long, Fig. 19 b). Clinocerinae

2 Last abdominal segment rounded, with small warts. Each wart has two or three long hairs. (Fig. 3 a). Chelifera Macquart, 1823

2* Dorso-lateral appendages on the last abdominal segment really short, apical appendages are long (Fig. 19 a). Hemerodromia Meigen, 1823 a

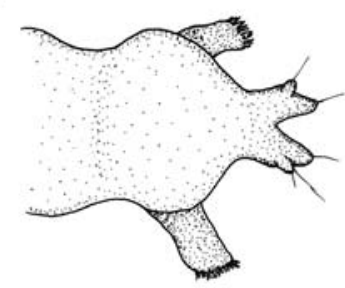

b

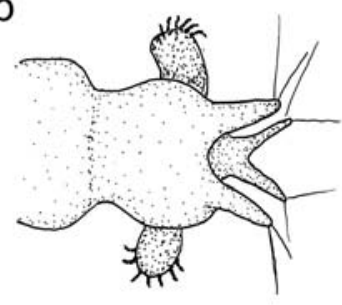

$1 \mathrm{~mm}$

Fig. 19. Empididae, last abdominal segment in dorsal view. (a) Hemerodromia Meigen, 1823, (b) Clinocerinae.

\section{Psychodidae:}

1 Larvae look pale, weak sclerotisation between the tergites, scleroticed plates on the tergites are in part remarkably reduced in size (Fig. 20 b-c).........Psychoda, Tinearia \& Jungiella (p.p.)

$1 *$ Larvae look dark, intensive sclerotisation between the tergites. (Fig. 20 a). ....Psychodidae Gen. sp.

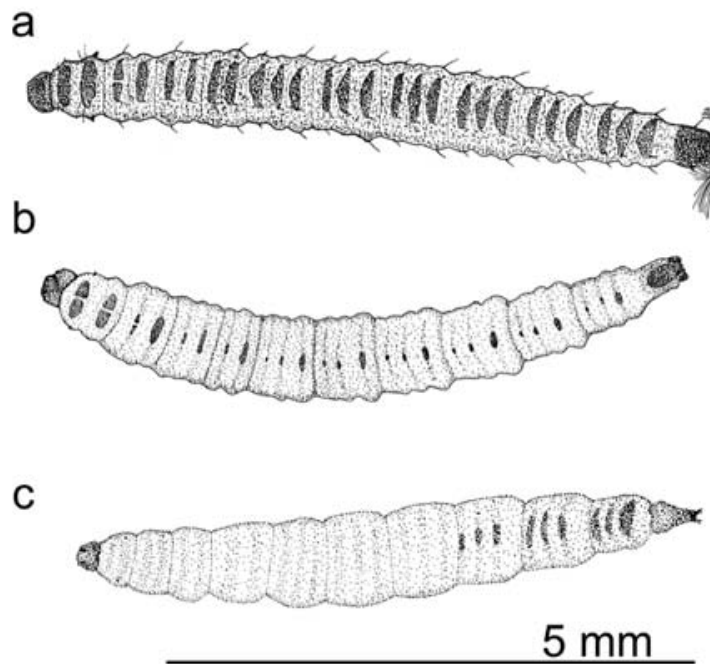

Fig. 20. (a) Psychodidae, (b-c) Psychoda, Tinearia \& Jungiella, Psychodidae.

\section{Simuliidae:}

1 Head fan is missing, the anal sclerite is y-shaped (Figs 21 d, i). ...........Twinnia hydroides (Novák, 1956)

$1 *$ Head fan is present, the anal sclerite is $\mathrm{x}$-shaped (Fig. $21 \mathrm{a}, \mathrm{j}$ ).

2 The widest part of the cephalic apotome is just behind the centre; width of the postgenal cleft on the ventral side of the head capsule exceeds its depth. Cervical sclerites are fused to the head capsule, central tooth of 
the hypostomium is tripartite (Figs 21 b, e, 1)......Prosimulium Roubaud, 1906

2* The widest part of the cephalic apotome is at its base; width of the postgenal cleft does not exceed its depth. Cervical sclerites separated from the head capsule, hypostomium with single central tooth (Figs $21 \mathrm{c}, \mathrm{f}, \mathrm{k})$. 3

3 Lobes of the gill spot are thick and running parallel to one another (Fig. $21 \mathrm{~h}$ ). Circle of hooks on the last abdominal segment bearing more hooks on the dorsal side than on the ventral side.Simulium (Wilhelmia) Enderlein, 1921

$3^{*}$ Lobes of the gill spot are thin and coiled (Fig. 21 g) or not yet visible (earlier instars). Simulium Latreille, 1802

\section{Stratiomyidae:}

1 Last abdominal segment rounded and with a hairy fringe (Figs 22, a-b), habitus as in Fig. 6 b.
$1^{*}$ Last abdominal segment looks different (Fig. 6 c). 3

2 Hairy fringe along posterior edge of the abdominal segment interrupted by a central gap (Fig. 22 b). Beris vallata (Forster, 1771)

$2 *$ Uninterrupted hairy fringe on the anal segment (Fig. 22 a). Beris clavipes (Linnaeus, 1767)

3 Indentation on the basis of the last abdominal segment (Fig. 22 c). Nemotelus Geoffroy, 1762

$3 *$ Last abdominal segment is elongated, round or right-angled, but always without a hairy fringe and never constricted (Fig. 6 c, 22 d); last abdominal segment not as in Figs. 22 a-c.......Stratiomyidae Gen. sp. (p.p.)

\section{Tabanidae:}

1 Four pairs of pseudopodia on each abdominal segment (Fig. 23 a). Tabanidae Gen. sp. (p.p.)

$1^{*}$ Three pairs of pseudopodia on each abdominal segment (Fig. 23 b). Chrysops Meigen, 1803 a

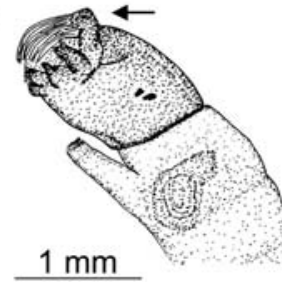

d

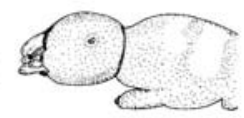

b

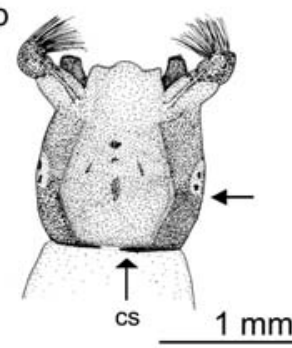

e

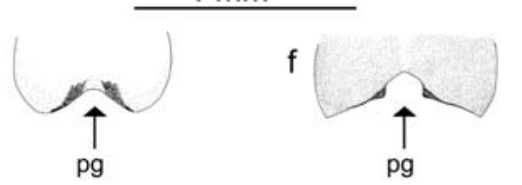

i c

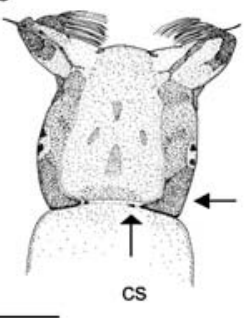

pg

g

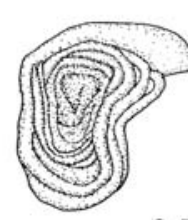

$\mathrm{h}$

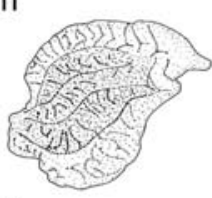

$0.5 \mathrm{~mm}$

i
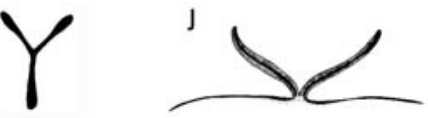

$0.5 \mathrm{~mm}$

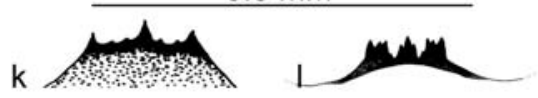

Fig. 21. Simuliidae. (a) Head in lateral view, (b) Prosimulium Roubaud, 1906, dorsal view, (c) Simulium Latreille, 1802, dorsal view, (d) Twinnia hydroides (Novák, 1956), lateral view, (e) Prosimulium, part of head capsule, ventral view, (f) Simulium, part of head capsule, ventral view, (g) Simulium, gill spot, (h) Simulium (Wilhelmia) Enderlein, 1921, gill spot, (i) Twinnia hydroides, anal sclerite, (j) Simuliidae, anal sclerite, (k) Simulium, hypostomium, (1) Prosimulium, hypostomium. Explanations: $c s=$ cervical sclerite; pg $=$ postgenal cleft. 

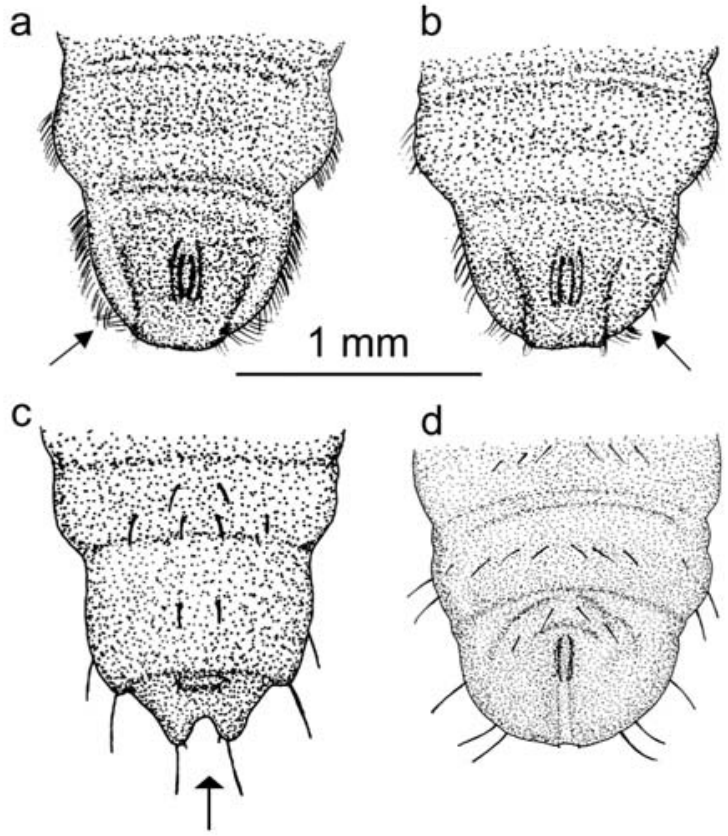

Fig. 22. Stratiomyidae, last abdominal segments, ventral view. (a) Beris clavipes (Linnaeus, 1767), (b) Beris vallata (Forster, 1771), (c) Nemotelus Geoffroy, 1762, (d) Stratiomyidae.
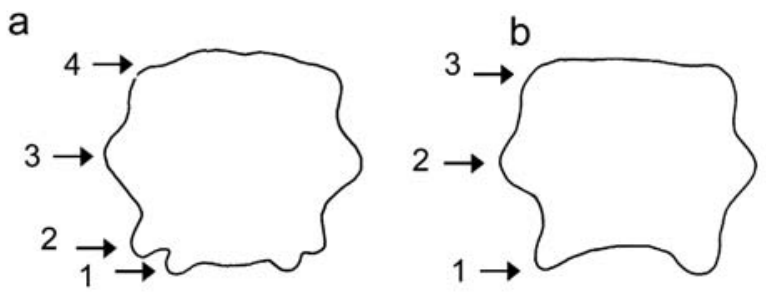

Fig. 23. Schematic cross section of an abdominal segment. (a) Tabanidae, (b) Chrysops Meigen, 1803, Tabanidae.

\section{Tipulidae:}

1 Dorsal lobes of the spiracular field on the last abdominal segment are narrowed, two pairs of anal papillae (Fig. 24). Dolichopeza albipes (Ström, 1768)

$1 *$ Dorsal lobes of the spiracular field not conspicuously narrowed, lobes cylindrical or flattened, sometimes reduced (Figs $10 \mathrm{~b}$-d). Two to four pairs of anal papillae, sometimes inconspicuous....Tipula Linnaeus, 1758

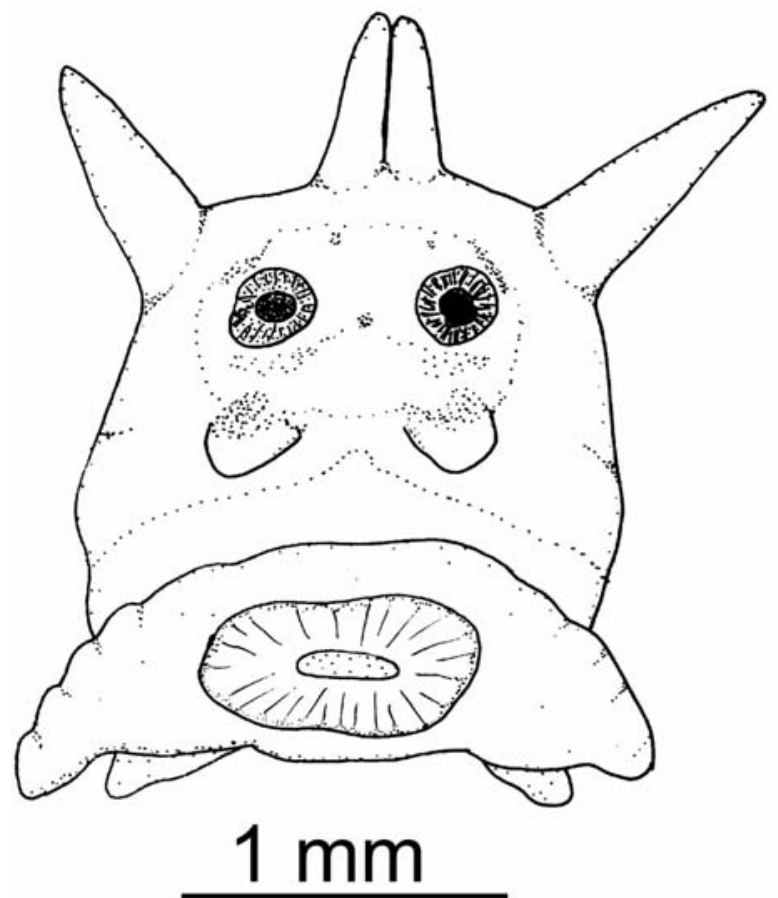

Fig. 24. Dolichopeza albipes (Ström, 1768) (Tipulidae), spiracular field. Modified according to Theowald (1967).

\section{Limoniidae/Pediciidae:}

1 Spiracular field with only two lobes (Figs $25 \mathrm{c}, \mathrm{e}$ ).

$1 *$ Spiracular field with more than two lobes. ..........5

2 Creeping welts on the dorsal and ventral side of abdominal segments 2-7. (Fig. $3 \mathrm{~b}$ and $25 \mathrm{f}$ ). Spiracles on the last abdominal segment are missing............Antocha Osten-Sacken, 1860

$2 *$ Pseudopodia or creeping welts are only on the ventral side of the abdominal segments. Last abdominal segment with spiracles.

3 Lobes short, spiracular field large (Fig. 25 e). Abdominal segments with creeping welts. ......Tricyphona Zetterstedt, 1837

3* Lobes longer, spiracular field small (Fig. 25 c). Abdominal segments with pseudopodia or protuberances.

4 Abdominal segments with paired pseudopodia with hooks on the apical end of each pseudopodium (Fig. $25 \mathrm{~b})$. Dicranota Zetterstedt, 1838

4* Abdominal segments with paired wart-like protuberances on the ventral site. Protuberances without hooks. (Fig. 25 d). 
a

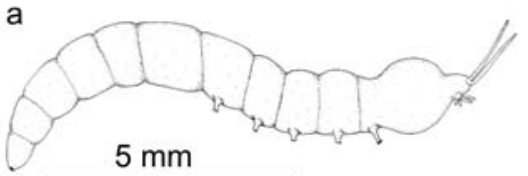

b

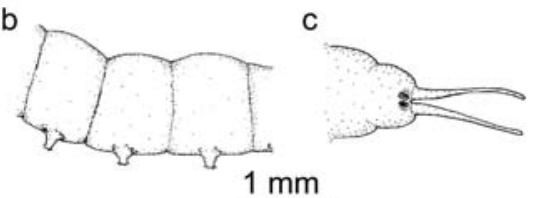

d
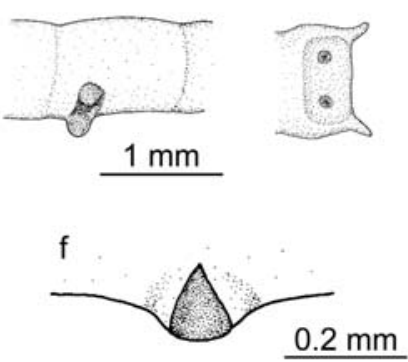

Fig. 25. Limoniidae. (a-c) Dicranota Zetterstedt, 1838, (a) habitus (b) pseudopodia, lateral view (c) last abdominal segment, dorsal view, (d) Pedicia Latreille, 1809, wart-like protuberances, (e) Tricyphona Zetterstedt, 1837, last abdominal segment, dorsal view, (f) Antocha Osten-Sacken, 1860, creeping welt.

5 Spiracular field with 5 lobes.

$5^{*}$ Spiracular field with $\leq 4$ lobes.

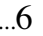

6 Five lobes which are extensively pigmented black, spatulately shaped with an lightly serrated edge (Fig. $26 \mathrm{f}$ ). (Abdominal segments without creeping welts. Habitus as in Fig. 26 b.). Scleroprocta Edwards, 1938

6* Lobes not as in Fig. $26 \mathrm{f}$. 7

7 Five cylindrical lobes, dark brown, with a charateristic fringe of hairs (Fig. 26 g). Habitus as in Fig. 26 c. Rhypholophus Kolenati, 1860

7* Lobes different than described above. ...Limoniidae Gen. sp. (p.p.)

\section{Triplet}

8* Four lobes, all of equal length, slender and fingershaped (Fig. 26 d). Abdominal segments without creeping welts, habitus as in Fig. 26 a. Eloeophila Rondani, 1856

8** Four lobes, dorsal lobes slightly shorter than the ventral lobes. Lobes with prominent hair fringes and a characteristic pigmentation (Fig. 26 e).......... Hexatoma Latreille, 1809

$8 * * *$ Lobes and spiracular field not as in Fig. $26 \mathrm{~d}$ or e, combination of characters not as described above; sometimes less than four lobes. Creeping welts can be developed on ventral side or additionally on dorsal side of the body. a
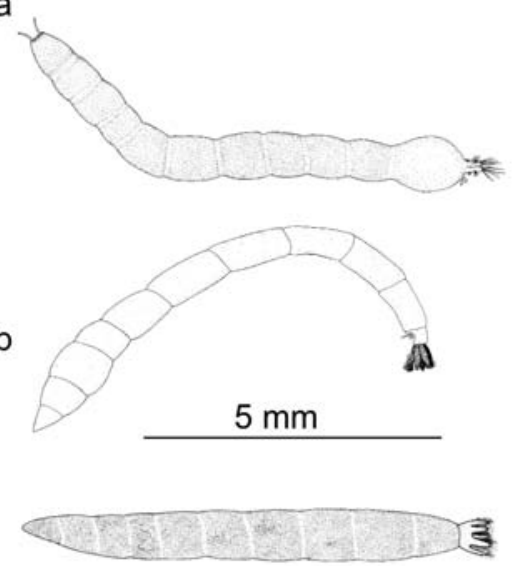

C d
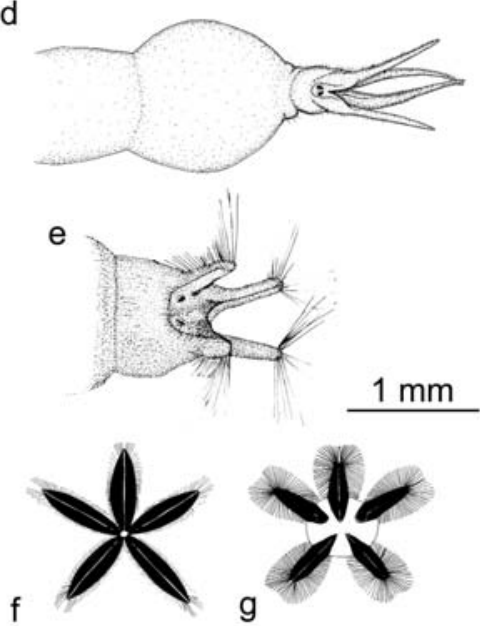

Fig. 26. Limoniidae. (a) Eloeophila Rondani,1856, (b) Scleroprocta Edwards, 1938, (c) Rhypholophus Kolenati, 1860, (d-e) last abdominal segment, dorsal view, (d) Eloeophila, (e) Hexatoma Latreille, 1809, (f-g) spiracular field, (f) Scleroprocta, (g) Rhypholophus 


\section{Acknowledgements}

This work was supported by the Länderarbeitsgemeinschaft Wasser (project number: LAWA O 4.02). We gratefully acknowledge the provision of material by our collegues Dr. A. Dettinger-Klemm and Dr. H. Zwick. Dr. H. Reusch, Dr. C. Orendt and Prof. Dr. R. Wagner are thanked for helpful suggestions and constructive criticism. Special thanks to Dr. Steffen Pauls for linguistic help.

\section{Literature}

Bass J. 1998. - Last-Instar Larvae and Pupae of the Simuliidae of Britain and Ireland: A Key with brief ecological notes. Freshwater Biological Association Scientific Publications 55.

Disney R. H. L. 1999. - British Dixidae (Meniscus midges) and Thaumaleidae (Trickle midges): Keys with ecological notes. Freshwater Biological Association Scientific Publications 56.

Frutiger A.\& Jolidon C. 2000. - Bestimmungsschlüssel für die Larven und Puppen der in der Schweiz, in Österreich und in Deutschland vorkommenden Netzflügelmücken (Diptera: Blephariceridae), mit Hinweisen zu ihrer Verbreitung und Phänologie. Mitteilungen der schweizerischen entomologischen Gesellschaft, 73, 93-108.

Haase P., Sundermann A., Schindehütte K. 2006. - Operationelle Taxaliste als Mindestanforderung an die Bestimmung von Makrozoobenthosproben aus Fließgewässern zur Umsetzung der EUWasserrahmenrichtlinie in Deutschland. www.fliessgewaesserbewertung.de

Haase P., Sundermann A., Hering D., Korte T., Meier C., Böhmer J. \& Zenker A. 2004a. - Anwendung und Erprobung neu entwickelter Verfahren zur Fliessgewässerbewertung (Makrozoobenthos). Report for the Länderarbeitsgemeinschaft Wasser (LAWA). www.fliessgewaesserbewertung.de

Haase, P., Lohse, S., Pauls, S., Schindehütte, K., Sundermann, A. Rolauffs, P. \& Hering, D. 2004b. - Assessing streams in Germany with benthic invertebrates: development of a practical standardised protocol for macroinvertebrate sampling and sorting. Limnologica, 34 (4), 349-365.

Hennig W. 1950. - Die Larvenformen der Dipteren. Vol. 2. Berlin.

Hennig W. 1952. - Die Larvenformen der Dipteren. Vol. 3. Berlin.

Illies J. 1978. - Limnofauna Europaea - Eine Zusammenstellung aller die europäischen Binnengewässer bewohnenden mehrzelligen Tierarten mit Angabe über ihre Verbreitung und Ökologie. Gustav Fischer, Stuttgart

Kniepert F.-W. 2000. - Insecta: Diptera: Tabanidae. Pages 111-204 in Süßwasserfauna von Mitteleuropa. Schwoerbel J. \& Zwick P. (eds.) 21, 19. Spektrum, Heidelberg.

Nilsson A. N. (eds.) 1997. - Aquatic insects of North Europe. A taxonomic handbook. Volume 2: Odonata, Diptera. Apollo Books, Stenstrup.
Papp L. \& Darvas B. (eds.) 1997. - Contributions to a manual of palaearctic Diptera. Vol. 2 Nematocera and Lower Brachycera. Science Herald, Budapest.

Papp L. \& Darvas B. (eds.) 1998. - Contributions to a manual of palaearctic Diptera. Vol. 3 Higher Brachycera. Science Herald, Budapest.

Papp L. \& Darvas B. (eds.) 2000. - Contributions to a manual of palaearctic Diptera. Appendix. Science Herald, Budapest.

Pottgiesser T. \& Sommerhäuser M. 2004. - Die Fliessgewässertypologie Deutschlands: System der Gewässertypen und Steckbriefe zu den Referenzbedingungen. 19. Erg.Lfg. 7/04, VIII-2.1: 1-16 in Handbuch Angewandte Limnologie. Steinberg C., Calmano W., Wilken R.-D. \& Klapper H. (eds.). ecomed Verlagsgesellschaft, Landsberg.

Rivosecchi L. 1984. - Ditteri (Diptera).Guide per il riconoscimento delle specie animali delle acque interne italiane. (Consiglio nazionale delle ricerche) Roma.

Rozkosny R. (ed) 1980. - Klíc vodních larev hmyzu. Ceskoslovenská Akademie Ved., Praha.

Rozkosny R. 2000. - Insecta: Diptera: Stratiomyidae. Pages 1-110 in Süßwasserfauna von Mitteleuropa. Schwoerbel J. \& Zwick P. (eds.), 21, 18. Spektrum, Heidelberg.

Rozkosny R. 2002. - Insecta: Diptera: Sciomycidae. Pages 15-122 in Süßwasserfauna von Mitteleuropa. Schwoerbel J. \& Zwick P. (eds.), 21/23. Spektrum, Heidelberg.

Saether O. 2002. - Insecta: Diptera: Chaoboridae. Pages 1-38 in Süßwasserfauna von Mitteleuropa. Schwoerbel J. \& Zwick P. (eds.), 21/10+11. Spektrum, Heidelberg.

Schumann H., Bährmann R. \& Stark A. 1999. - Checkliste der Dipteren Deutschlands. Entomofauna Germanica 2. Studia dipterologica Supplement, 2, 1-354.

Smith K.G.V. 1989. - An Introduction to the Immature Stages of British Flies. The Royal Entomological Society of London, London, Vol. 10, part 14,.

StatSoft Inc. 2002. - STATISTICA for Windows (Software-System for Data Analysis) Version 6.1. www.statsoft.com

Theowald B. 1967. - Familie Tipulidae (Diptera, Nematocera) Larven und Puppen. In Bestimmungsbücher zur Bodenfauna Europas. D'Anguilar J., Beier M., Franz H. \& Raw F. (eds.). AkademieVerlag, Berlin.

Wagner R. 2002. - Insecta: Diptera: Thaumaleidae. Pages 39-110 in Süßwasserfauna von Mitteleuropa. Schwoerbel J. \& Zwick P. (eds.) 21/10+11. Spektrum, Heidelberg.

Westheide W. \& Rieger R. (eds.) 1996. - Spezielle Zoologie, Teil 1: Einzeller und wirbellose Tiere. Gustav Fischer, Stuttgart. 